\title{
Spatial Representation in Product Modelling
}

\author{
Monjur M Mourshed, PhD Student \\ Denis Kelliher, Marcus M Keane, Lecturer \\ IRUSE, Department of Civil \& Environmental Engineering \\ National University of Ireland Cork. Cork: Republic of Ireland \\ m.mourshed@student.ucc.ie, d.kelliher@ucc.ie, marcus.keane@ucc.ie
}

\begin{abstract}
An unambiguous definition of space is necessary before any attempt made to clevelop product or process models for concurrent engineering in the AEC Industry. The ambiguity is the resuit of different and even conflicting approach to its definition in the various phases of the building life cycle for different stakeholders, e.g. Architects, Engineers, and Building Services Engineer etc. Some researchers consider space as an abstract property: of things, while others consider as a thing itself. Regardless of the definition, the space can be referred to as a collector of material objects and also as an object itself. This paper investigates the existing concepts \& criteria of definition in various phases, compares with the factual and ontological meaning, and specifies conceptual schemas for representation of space, geometry, and buildings.
\end{abstract}

\section{Introduction:}

\subsection{Building Product Model}

"A Building Product Model is potentially a richer representation than any set of drawings can be implemented in multiple ways, including an ASCII file or as a database. The data in the model will be created, manipulated, evaluated, reviewed, and presented using computer applications, some of which are extensions of the current computer-based design and engineering tools" [Eastman 1999]. The goal of product modelling is to allow the seamless movement of data (both physical and abstract, adequate for representing the building over all its life stages for all uses incurred) between existing and future $\mathrm{CAD} / \mathrm{CAE}$ applications by using a neutral and vendor independent file format, backend databases, and translators to and from that format. The file format in question will be an international standard accepted and agreed by the actors (commercial developers of software, users, manufacturers, contractors etc.) in the industry.

\subsection{Efforts at Product Modelling}

Mid - 1970's mark the beginning of efforts at developing integrated systems, based on a single building model supporting a suite of applications. The distinctive early efforts were OXSYS CAD, and SSHA-Edinburgh in UK and ARCH-MODEL, BDS, GLIDE in US. [Eastman 1999] It was later understood that a strong association was needed between these geographically distributed efforts, later gave birth to Non-Commercial and vendor independent alliance namely ISO-STEP (STandard for the Exchange of Product model data) and IAI (International Alliance on Interoperability). The schema of the former is called STEP hence the later one is called IFC (Industrial Foundation Classes). As AEC industry is the most diverse one in terms of construction method, skill, and fragmentation of the process, developing a single product model for information visualization is harder because of the various levels of detail, conflicting definition and expression.

\subsection{Concept of space}

Space is the basic element a designer starts with while designing any object. The first scratch on paper or sketchpad in CAD system is about space and its organization both in 2D and 3D. Even before selecting construction method and articulation techniques, a thorough understanding of space and its purpose is required. In the case of Building design and construction this is usually done in Architectural Programming phase, subsequent clarification is made to suit purposes as the design progresses.

As being a part of the material world, space is evident in every construct we build to visualize and perceive the surroundings. Already as infants we learn to know the extension of our own body and how it is spatially related to external things. Ekholm \& Fridqvist divided spatial experience into two: Experiential and Factual. The experience of space within a cubic room can be termed as factual whereas the feelings of space in an open field can be experiential. The later is subtle and depends on our 
imagination and we rely more fully on inter-subjective, often culturally defined, understanding of experiential space. [Ekholm \& Fridqvist 1997]

Neither in the old languages (space is derived from Latin 'spatium' and French 'espace') [Webster's 1995] nor in everyday speech today does the concept space have a single or clear-cut meaning. It may be referred to as: a) container with an existence independent of material objects, b) a relation among material objects, c) a geometrical concept, and d) a thing with certain spatial properties [Ekholm \& Fridqvist 1997]. Figure 1 shows the different kinds of spatial impressions we can get.
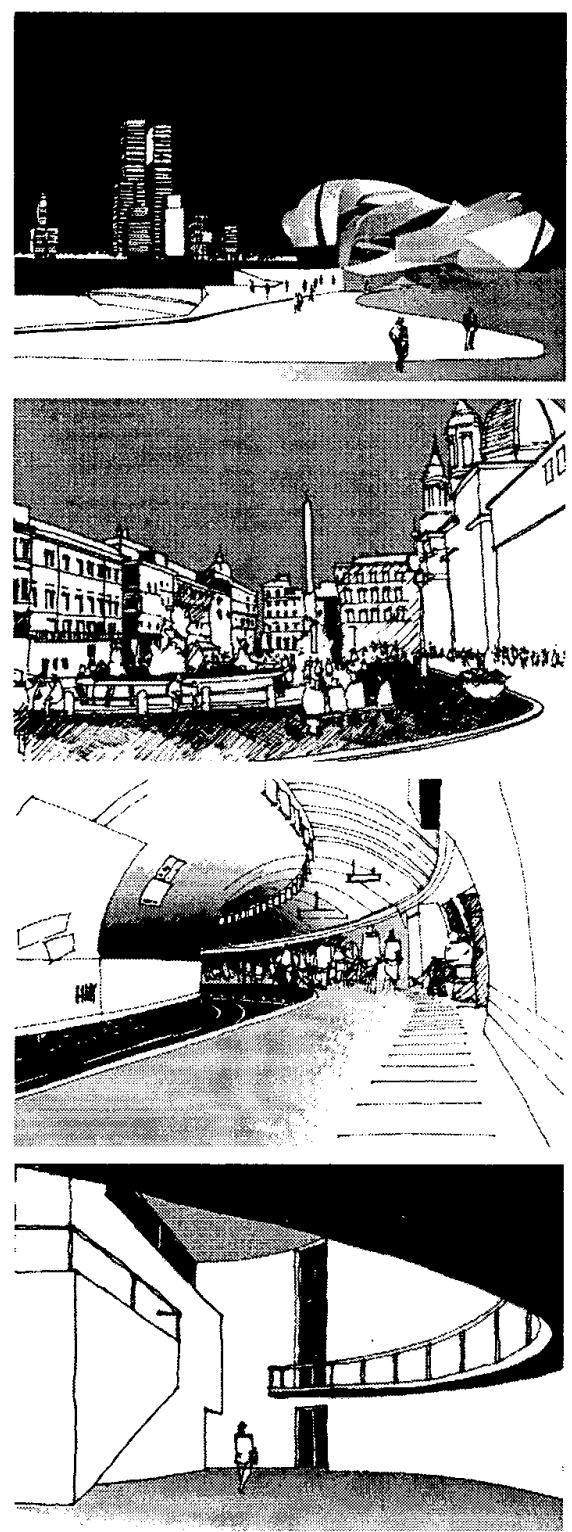

Figure1: Different Experience of Space 1.4. Requirements of space:

Table 1: Requirements of space in life-cycle stages

Scale: Requirement
$\begin{aligned} & \text { Experiential } \\ & \text { Expan: }\end{aligned}$




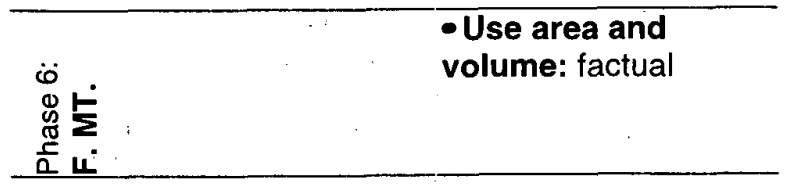

\section{Space \& Standards:}

There are differences in representation of space in the realm of information systems for building classification and building product modelling. ISO identifies space as concrete object with functions [ISO 1997] and in other product modelling efforts, it is classified as abstract object bounded by concrete building elements [Eastman \& Siabris 1995] This section will focus on the standards of representing Construction Entity and resulting space in two standards namely STEP and IFC.

\subsection{ISO-STEP}

ISO (International Standards Organization) defines space as "Three dimensional, material construction result, contained within or otherwise associated with a building or other construction entity. A space may be bounded physically or notionally." [ISO 1997] A schema produced of the definition by Ekholm \& Fridqvist as follows:

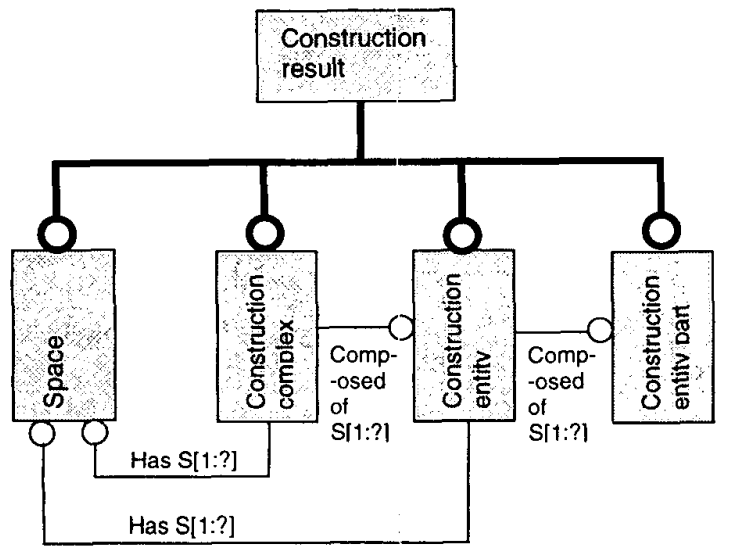

Figure 2: Relations of space to other construction results - ISO

Here space is seen as a constituent part or aspect of but again construction entity bathroom) also have spaces the construction resul part (e.g., prefabricated built in them. The conflict is that, 'Construction Entity
Space' is composed of 'Construction Entity Parts' and again certain 'Construction Entity Part' contains 'Construction Entity Space'. Here the class 'space' can be in two different levels and break the rule that classes of the same rank must be disjoint [Ekholm \& Fridqvist 1996].

\subsection{IFC}

Space may be seen either as a property or as a thing having property. In IFC (Industrial Foundation Classes) space is seen as a property of the IfcElement not as an object itself. Though IFC release 2.0 identifies and defines Architectural Space Programming and terms as IfcSpaceProgram group, which can be manipulated defining adjacency to each other and can contain data of various life-cycle phases. IfcSpace must be an abstract intermediary concept applied "ad hoc" rather an attempt to develop a true representation of reality. [Ekholm Fridqvist 1997] A schema of the same shown below in Figure 3:

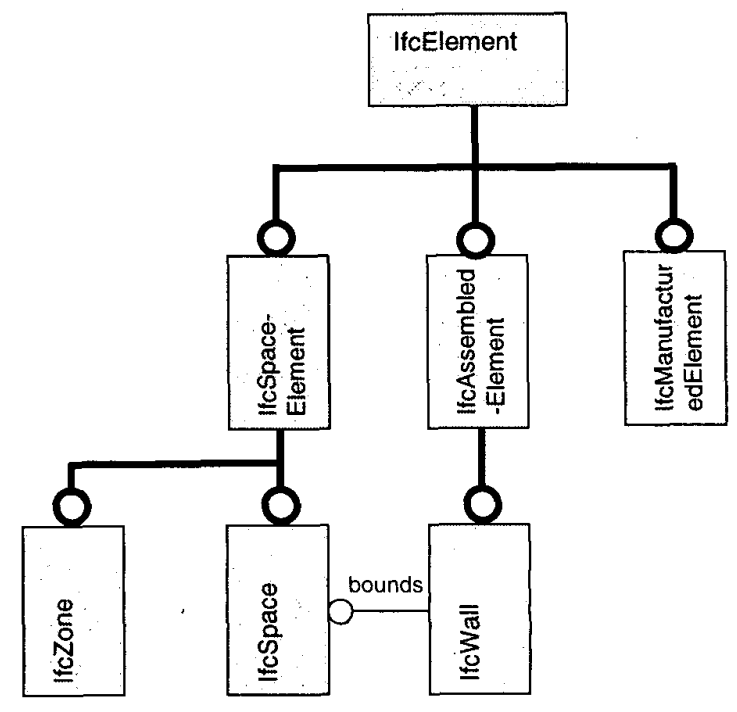

Figure 3: IfcSpace

\section{Various efforts on Spatial Modelling}

Three approaches to spatial modelling, which represents a considerable difference are considered in this paper: Björk [1992]

Eastman and Siabiris [1995]

Ekholm and Fridqvist [1997]

\subsection{Proposition of Björk}

According to Björk [1992], the concept of space can be defined in two complimentary ways: "One is based on the complete physical separation of the space from other spaces by physical obstacles which provide visual, acoustic and inner climate shelter. Another way of defining space is as the locus of a homogenous activity." To define space Björk introduced a intermediary layer between space and space boundary, and is called 'shell'. Here, each space is enclosed in a 'shell' and the physical 
structures (walls, floors) enclosing the space are behind the shell. The three levels of 'space boundaries' are thus formed: "Patches with a uniform surface, space boundaries shared by exactly one enclosing structure and one space and space boundary assemblies." A strongly reduced version of the schema developed by Björk presented by Ekholm and Fridqvist [1997] is presented in Figure 4:

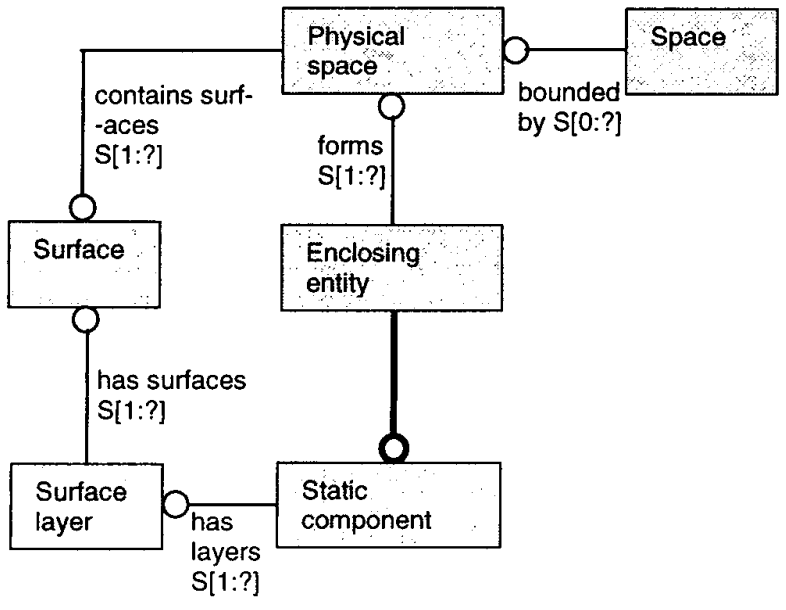

Figure 4: Björk's schema

\subsection{Eastman and Siabiris}

To add various building typologies, construction technologies or stylistic criteria a flexible kernel was conceptualised based on three following component concepts of building [1995]:

CONSTRUC'TED_FORM, Material used in construction of the building: bricks, glass, mechanical equipment etc.

BOUNDED_SPACE, supported and bounded by CONSTRUCTED_FORM, defining areas of human occupancy and use, and

ACTIVITY, general (business lease space) and specific (e.g. president's office)

As seen in Björk's model, this approach also embodies a concept of BOUNDED_SPACE as a "conceptual and formational link" between a building's CONSTRUCTED_FORM and its ACTIVITYs. "BOUNDED_SPACEs are the enclosed regions within a building that are available to accept human activity, bounded on all sides. The boundaries modulate the dimensions of light, colour and texture, thermal energy and so forth, defining the properties of the space enclosed." Ekholm and Fridqvist relate these concepts in a schema described in Figure 5.
The discrepancy of the model lies in the fact that, spatial properties of activities are expressed multiple times. For example the same surface of an element (e.g. inside of a door) need to be related in CONSTRUCTED_SPACE and USE_SPACE. This need for consistency checking makes the model redundant. [Ekholm \& Fridqvist 1997]

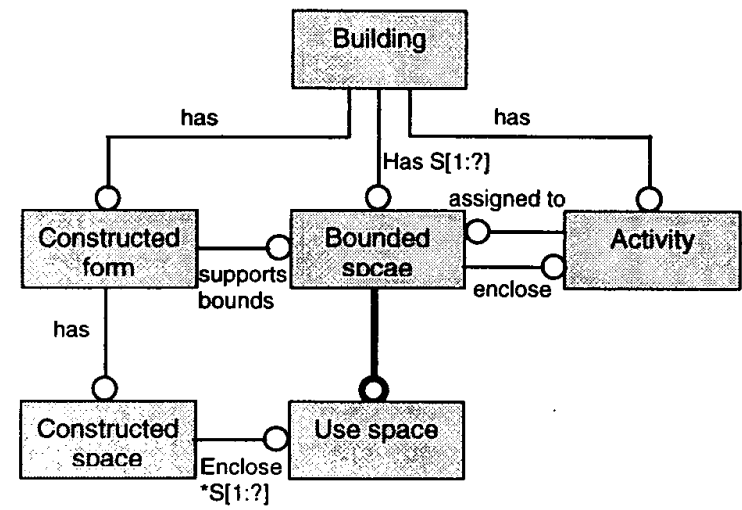

Figure 5: Basic concept in Eastman and
Siabiris's paper

\subsection{A new approach by Ekholm and Fridqvist}

Ekholm \& Fridqvist after an in-depth ontological analysis of the spatial requirements in different phases on the life cycle, proposed a new schema for building information systems. Buildings are considered as construction entities with enclosed places or spaces. These spaces again are characterised both by spatial properties like area and volume, and by enclosing properties, e.g. enclosing to light, sound, air or fire. Enclosing is not necessarily a material property but may also be dependent on a person's interpretation. A space function program developed in architectural programming contains requirements on the buildings spaces, e.g. surface materials, fire resistance and sound reduction levels. Spaces are classified by their basic functions.

This schema represents Construction entity space as an aspectual part of a construction entity like load bearing, heating or electrical system. The construction entity space is composed of Construction entity parts, which are composed of Element parts. Both Construction entity space and its parts have Shape and Spatial relations to other entities of the same kind. The shape of the Construction entity space is based on the shape of the Construction entity parts and their spatial relations. Topology, position, and dimensions define shape [Ekholm \& Fridqvist 1997]. Their schema is shown in EXPRESS notation in Figure 6. 
In this schema, space can also be related to each other in two ways: adjacency and surrounding and allows manipulation of various set of relations among the spaces in the buildings like indoor-outdoor, living-services, utility-use and so on.

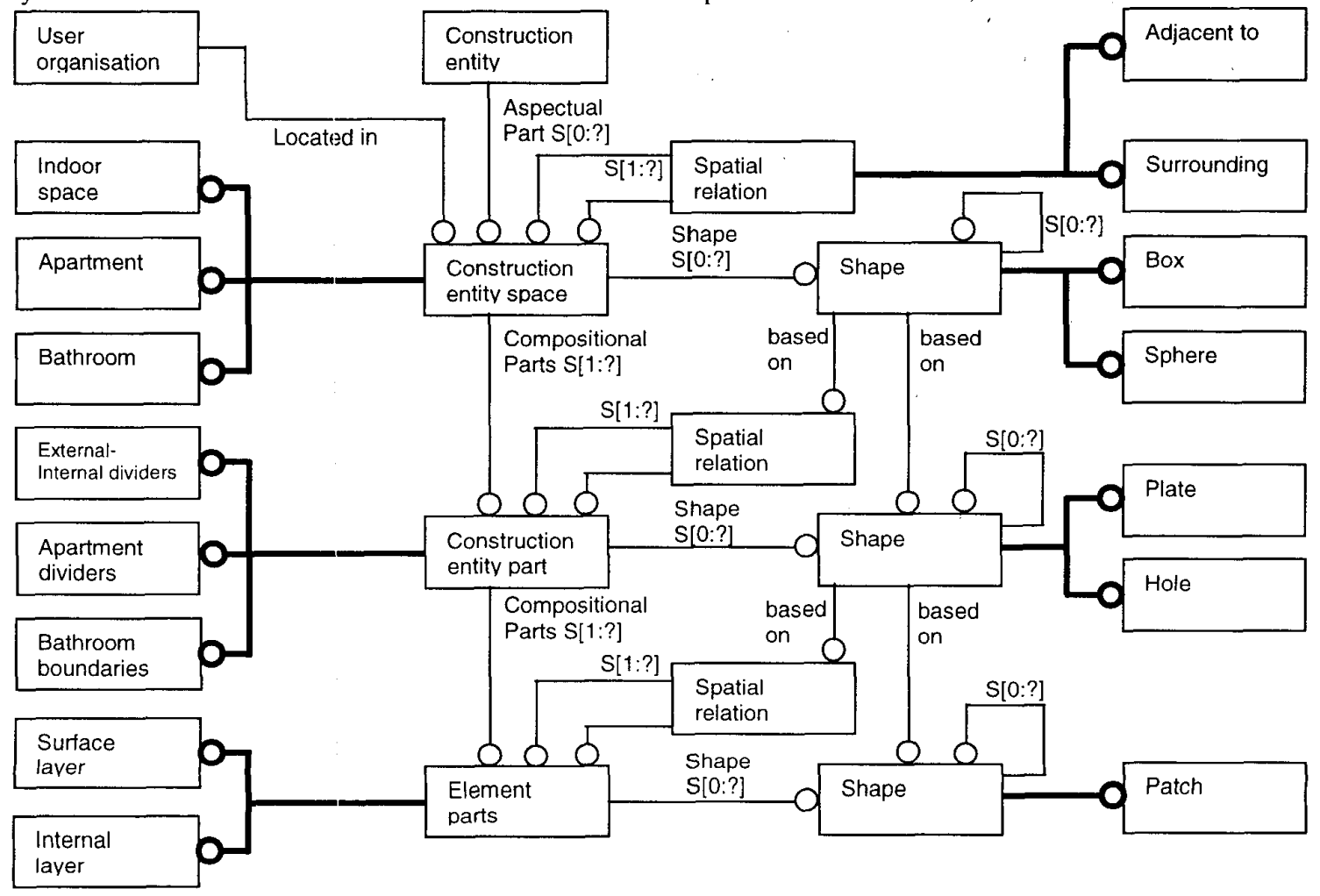

Figure 5: Schema of E:kholm and Fridqvist

\section{Conclusion}

Defining space has been hard work for developers and researchers because of its complexity in representation. The various efforts analysed here are the launch pads for further research. Most of the concepts are limited to their use in terms of fields and specialization. To develop an acceptable representation encompassing all the phases should consider the following:

Björk's idea of typical requirements should be stated here as it is still the philosophy behind product modelling: "There should also be clear distinction on the entity level between subparts of enclosed spaces and assemblies of spaces (such as apartments, fire zones and heating zones)" [Björk 1992]

Space can be represented as an aspect of the construction entity and construction complex.
The class for describing space should be defined in such a way that it does not conflict with the constituent spaces (Space bounded by a wall and space enclosed in a prefabricated bathroom, a construction element like wall). 
[2] Boman M., Bubenko J., Johannesson P., and Wangler B. (1993). Models, concepts and information. Department of computer systems and sciences, Stockholm University, October 1993, fifth edition.

[3] Eastman C.M. and Siabiris A. (1995). A generic building product model incorporating building type information. Automation in Construction, vol. 3, no. 4, pp. 283-304

[4] Eastman C.M. (1999). Building Product Models: Computer Environments Supporting Design and Construction. Florida: CRC.

[5] Ekholm A. (1996). A conceptual framework for classification of construction works. Electronic Journal of Information Technology in Construction (ITCon) Vol.1. pp 31-50. Stockholm: Royal Institute of Technology.

http://www.itcon.org/1996/2/

[6] Ekholm A., Fridqvist S. (1997). Concepts of Space in computer based product modelling. $15^{\text {th }}$ ECAADE Proceedings.

http://www.tuwien.ac.at/ecaade/proc/ekholm/ekholm.htm

[7] IAI (International Alliance for Interoperability) 2000 IFC Technical release 2.0 .

http://iaiweb.lbl.gov/

http://cic.vtt.fi/niai/technical/lFC_2.0/index.htm

[8] ISO (1997) ISO/CD 12006-2 Building constructionOrganisation of information about construction worksPart2: Framework for classification of information. Draft ISO Standard 20 $0^{\text {th }}$ May 1997. Newcastle Upon Tyne: NBS Services.

[9] Katranuschkov P. (1997). Interoperability of Heterogeneous Building Product Models.

http://cib.bau.tu-dresden.de/ peter/proj-kurz/rep 1-97.htm

[10] Webster (1995). Websters New Collegiate Dictionary. Springfield Massachusetts: G.\&C. Merriam Company.

\section{Note:}

All schemas in this paper are produced/ reproduced using EXPRESS - G notation.

www.steptools.com 